\title{
Provision of mental health support for medical students
}

This article was published in the following Dove Press journal:

Advances in Medical Education and Practice

\section{Varun Kothari \\ Natalie George \\ Osama Hamid}

Faculty of Medicine, Imperial College London, London, UK
Correspondence: Varun Kothari Faculty of Medicine, Imperial College London, Exhibition Road, South Kensington, London, SW7 2AZ, UK Email varun.kothari13@imperial.ac.uk

\begin{abstract}
Studying medicine at university requires hard work and motivation. The medical school curriculum is vast, and as well as being academically rigorous, also holds emotional challenges. This can predispose students to mental health issues, which include depression and suicidal thinking. Since these are significant issues, we feel it is important to highlight the reasons behind them, and the options available to students to deal with them.
\end{abstract}

Keywords: mental, health, medical, student, support, well-being

\section{Introduction}

Every year thousands of students leave school and start university as medical students, embarking on a journey that will culminate in them becoming doctors. This journey, however, is a long one, requiring a strong work ethic and immense dedication. As well as the amount of study, medical school is also often emotionally challenging. From learning via dissection to hospital placements, students are exposed to suffering and death from an early stage. Having to deal with these challenges, it is only natural that students are predisposed to mental health issues. Indeed, $30 \%$ of medical students had experienced mental health problems, yet more than $80 \%$ said that they felt undersupported. ${ }^{1}$ These problems can range from depression to suicidal ideation, thus having a damaging effect on the quality of life. ${ }^{2}$ In this article, we discuss why this might be the case and talk about how students may be able to obtain support early on. ${ }^{1}$

\section{Discussion}

Medical students experiencing mental health concerns often do not vocalize them, for various reasons. For example, there are myths surrounding mental health and fitness to practice. Some people feel that having a mental health condition automatically bars them from practicing as a doctor, while others feel that they may be discriminated against if they divulge their issues. However, in reality, this is not the case. The General Medical Council clearly states "in almost every case, a mental health condition does not prevent a student from completing his or her course and continuing a career in medicine."3

Some students also do not want to appear weak. Progressing through medical school requires the highest of academic standards, ${ }^{4}$ so some may feel that by reporting their issues, it may come across as though they are looking for an "excuse" to avoid studying. Additionally, stigma surrounding mental health problems at medical school is surprisingly high. ${ }^{5}$ In a survey, $30 \%$ of early years' students reported that this was an explicit barrier 
to their use of mental health services. ${ }^{6}$ It is somewhat paradoxical that medical students are taught to treat mental health issues in the same way as physical issues, yet when it comes to themselves, the stigma surrounding it is as strong as ever. ${ }^{7,8}$

Having highlighted some of the reasons why students are reluctant to seek help, we will detail some of the options available to students. Universities advise that students' first port of call for support should be their personal tutor. Their role is to offer academic, health, and financial guidance. Students are encouraged to meet at least once a term with their tutor to discuss any active issues they may be facing. Rapport built with personal tutors is therefore immensely significant in promoting mental wellbeing.

Mental Health Awareness Week is another prominent feature designed to tackle stigma around mental illness. Its purpose is not only to help those who are suffering from problems but also to allow students to identify peers who may be suffering. Online campaigns are alternative avenues to help students who are less likely to speak out. By allowing students to share stories anonymously, others may be more encouraged to reach out for help. Knowing they are not alone can help alleviate fears that their mental health will hinder their education or career.

\section{Conclusion}

From our experience, there is a wide array of help available to students to help combat mental health issues. The highly academic nature of the subject, as well as the emotional aspect of dealing with patients on attachments, means that mental health is a problem that needs to be addressed. In this article, we have explored some of the reasons students may find it difficult to seek help and some of the support that is available to them.

\section{Disclosure}

The authors report no conflicts of interest in this work.

\section{References}

1. Billingsley M. More than $80 \%$ of medical students with mental health issues feel under-supported, says Student BMJ survey. Student BMJ. 2015;23:h4521.

2. Rotenstein LS, Ramos MA, Torre M, et al. Prevalence of depression, depressive symptoms, and suicidal ideation among medical students: a systematic review and meta-analysis. JAMA. 2016;316(21):2214-2236.

3. General Medical Council and Medical Schools Council. Supporting medical students with mental health conditions; 2013. Available from: www. gmc-uk.org/Supporting_students_with_mental_health_conditions_1114. pdf_53047904.pdf.

4. General Medical Council. Guidance on UK medical education delivered outside the UK; 2009. Available from: https://www.gmc-uk.org/-/ media/documents/UK_medical_education_delivered_overseas_FINAL. pdf_28119232.pdf_56454529.pdf.

5. Munn F. Medical students and suicide. Student BMJ. 2017;2:j1460.

6. Givens JL, Tjia J. Depressed medical students' use of mental health services and barriers to use. Acad Med. 2002;77(9):918-921.

7. Goel N, Malhotra V, Tripathi Y. Sleep habits among first year medical students. J Evol Med Dent Sci. 2016;5(38):2276-2278.

8. Boni R, Paiva CE, de Oliveira MA, Lucchetti G, Fregnani J, Paiva BSR. Burnout among medical students during the first years of undergraduate school: Prevalence and associated factors. PLoS One. 2018;13(3):e0191746.
Advances in Medical Education and Practice

\section{Publish your work in this journal}

Advances in Medical Education and Practice is an international, peerreviewed, open access journal that aims to present and publish research on Medical Education covering medical, dental, nursing and allied health care professional education. The journal covers undergraduate education, postgraduate training and continuing medical education

\section{Dovepress}

including emerging trends and innovative models linking education, research, and health care services. The manuscript management system is completely online and includes a very quick and fair peer-review system. Visit http://www.dovepress.com/testimonials.php to read real quotes from published authors. 